\title{
On Tools and Representation
}

\author{
Gereçler ve Temsil Üzerine
}

\author{
Betül ORBEY, Sinan Mert ŞENER
}

Technology and tools have contributed a great deal to human evolution in terms of how we think, live, and work. The design domain has also witnessed and experienced changes in technology and design tools. Once a "master-builder," the architect has today become merely a designer, as fundamental tools of design introduced to the profession, such as paper and standardized line weight lead pencils, have drawn the architect away from the construction site and closer to the drawing board. Similar examples led researchers such as Visser to define the domain of design as having certain commonalities as well as distinct characteristics, depending on the design situation. In the same vein, this study takes the design tool as a design variant and investigates how it has affected the way architects present their work. To achieve this, issues of Yapı magazine from 1973-2015 were retrieved and representational graphics of projects published were categorized. It was noted that after the introduction of 3-dimensional representations in the 1990s, the use of more realistic diagrams and images grew, and this led to the reconstruction of the relationship between the architect and his audience, and made it a more inclusive, experiential and process-oriented relationship.

Keywords: Architectural design; design representation; design tool.

Öz

Teknoloji ve gereçler insanlığın evrimine çeşitli açılardan etki etmiş, nasıl düşündüpümüz, nasıl yaşadığımız ve nasıl çalıştığımız, kullandığımız ve geliştirdiğimiz gereçlerle değişmiştir. Tasarım süreçleri ve mimarlık pratiği de bu değişimi deneyimlemiştir. Bir zamanlar "yapı-ustası" olan mimar, kağıt ve stardize edilmiş kalem kalınlıklarının tasarım ortamına girmesi ile inşa sürecinden kopmuş, çizim masasında vakit geçirir olmuş. Zaman içinde gelişen teknolojiler ise, Visser gibi araştırmacıların tasarım sürecinin ortak özellikleri olmakla birlikte, tasarım ortamına göre tasarım değişkenlerine bağlı olarak farklı biçimlere bürünebileceğini öne sürmüştür. Bu çalışma da, tasarım gerecini bir değişken olarak ele alarak, mimarın iletişim biçimlerini nasıl değiştirdiğini irdeler. Bunun için Yapı dergisi 1973-2015 yılları arasında taranmış ve yayınlanan projelerin temsil tipleri üzerinden bir okuma yapılmıştır. Buna göre, 1990'lı yıllarda ilk kez görülen 3 boyutlu modellerle beraber, şemalar, 3 boyutlu gerçekçi anlatımlar ve betimleyici grafikler görülmeye başlanmıştır. Öncesinde uygulama çizimi tadında ve sadece mimar kişilerin anlayabildiği çizimlerin artık yerlerini açıklayıcı, sürece mimar olmayan kişilerin de dahil olabildiği, süreç gelişiminin öne çıktığı keşif dürtüsünü tetikleyen temsillere bıraktığı görülmektedir.

Anahtar sözcükler: Mimari tasarım; temsil; tasarım gereçleri.

İstanbul Technical University, Architectural Design Computing Program, İstanbul, Turkey.

Article arrival date: February 01, 2016 - Accepted for publication: May 25, 2016

Correspondence: Betül ORBEY. e-mail: betul.orbey@gmail.com

๑ 2016 Yıldız Teknik Üniversitesi Mimarlık Fakültesi - @ 2016 Yıldız Technical University, Faculty of Architecture 


\section{Introduction}

Technology has undeniable impacts on our environment. It has shaped the tools that we think through thus; have re-shaped the way we think, live, work and design.

The notion of "generic design" proposes that there are great similarities between design acts (Goel \& Purcell 1998) independent of the domain (Zimrig \& Craig, 2001). On the contrary, there are opinions supporting the presence of significant differences depending on design situations (Visser, 2009). Visser (2009) augments the notion of generic design and states that there are different forms of design. She defines three dimensions as sources of differences in design consisting of the process, the designer and the artifact with relevant subsets to each. Among these, this study will elaborate on a subset defined under the process dimension: tool.

This study inspires from the idea that representations constructed within the premises of what the tool affords, in turn affects the way a designer moves between the branches of a mental tree consisting of all the possible design solutions in his mind. As technology evolves and provides us with new tools to design, it changes what we design, how we design and how we communicate design.

This study is the first part of a PhD study. It attempts to construct a theoretical framework taking tools as design variant and starts investigating the relation between external representation and design tools before studying tools in terms of their impact cognitively.

\section{How Technology Impacts How We, Work and the Case of Architectural Practice}

Establishment of the assembly line marks the turning point in shaping the way that we work. The indicator of full mechanization is the assembly line, in which the factory is divided into an organism that works in smaller pieces. (Giedion, 1969) The assembly line develops around the idea of organization. Therefore it has required the study of the way work is performed by a worker in terms of physical motions. These motion studies of the human body when performing a task have freed the worker to substitute for any movement of the machine, and assigned him the role of assisting production as a controller. (Giedion, 1969)

This forces us to question what role is left to the human operator. Ingold underlines that mechanization restructures the organization of production from a "purely subjective" to a "purely objective" (Ingold, 2000) setting which pushes the human agency from the centre to the periphery of the fabricative process.

The effect of rationalization in the factory has also extensions in the architecture profession in the form of removing the creative part of making from physical involvement between work-man and building, and giving him a new role within the intellectual process of design (Ingold, 2000).

The architect, previously the "master builder", is now solely the designer of the structure which is the responsibility of the industry to put up. (Coleman, 1988) "The architect designs the house the builder implements the architect's design. One creates but does not implement; the other implements but does not create." (Ingold, 2000)

As the labor distribution and the roles within the profession changed, it made changes in procedures and representation inevitable. In the past, scale drawing or physical model of the project was enough to guide the builders and allow them to understand the design rules. This is no longer true in the age of mechanization, where design and construction information are so far apart from each other that highly detailed drawings of the design as a whole are required to achieve compliance and unity between the design and the building itself (Gregotti, 2010).

How Technology Impacts How We Represent Architecture?

Printing technology is one of the strongest influences that have affected the cognitive practices of human, through how we think in different modes. In McLuhan's view, each medium of communication reveals a distinctive way of perceiving the world thus, "the medium is the message." Volti (1992) proposes that reading produces an egocentric view of the world. Therefore, after the invention of printing, books have become ubiquitous and it has endorsed the readers to think in solitary and private rather than collectively (Volti, 1992) as it had been in storytelling times.

In similar fashion, the visual arts during the post-printing era began to describe scenes as they could be seen from a single point. Given this single view point, the scene appears to have a three-dimensional quality through the perspective rules rather than flatness intrinsic to medieval painting. In medieval painting figures were not painted according to the rules of perspective, but in accordance with the importance of the subjects publicly or theologically.

Until the development of printing rules of perspective were not utilized as printing and widespread reading had not conditioned people to see the world as it might be viewed from a single vantage point yet. The rules of perspective were developed and utilized as printing brought an individualistic world perception. (Volti, 1992)Therefore, there is no doubt that technology and tool have impact on both how we think and represent and that how we represent is indicative of our thoughts.

In some activities the entities and relationships the representations make explicit become the concepts designers think with. (Stacey \& Lauche, 2004) Therefore we 
can say that tools of architectural representation are also never neutral. They inherit the tendencies and beliefs of a particular time and place. These tools, and therefore these beliefs, "underlie the conception and realization of architecture." (Perez-Gomez \& Pelletier, 1997) Changing processes, methods and tools changes designers' tasks and information needs. (Stacey \& Lauch, 2004) New methods, procedures and computer tools require designers to represent design information differently and think about old problems in new ways. (Stacey \& Lauche, 2004). This is strongly evident after the emergence of paper and lead pencils with standard line weights.

Frascari reveals that paper although a robust yet cheap drawing support, has changed the way architecture was conducted by allowing architects to practice the profession away from the site and in front of the drawing board. Therefore, the early architectural drawings consist of procedures to be replicated during on site construction. Thus, the small movements of the architect at the drawing board are taken as analogous to the big movements of the mason during constructing buildings. (Piedmont-Palladino, 2007)

This is clearly evident in Louis Kahn's writing "on stopping our pencils." He advises architects to "train ourselves to draw as we build, from the bottom up, when we do, stopping our pencil to make a mark at the joints of pouring or erecting (because) in architecture, as in all art, the artist instinctively keeps the marks which reveal how a thing was done."

Conté's innovation of a spectrum of pencil weights from $\mathrm{B}$ to $\mathrm{H}$ has marked the second milestone after the invention of paper and pulled the architect one step further from the tactile flow of information within the practice. Previously, drafters practiced the technique of twisting the pencil along the straight edge to come up with a perfect line. Drawing a straight line was only part of the problem because; before technical pens and the computer, line weight was varied literally through the weight of the hand of the draft-person.

Each of these new technologies and tools may seem to pull the architect apart from the hands-on nature of the practice a step further. However, loss of certain habit or skills is not necessarily a bad thing. On the contrary, this may be the way that architects survive in an information rich architectural practice. Thus, it enhances other skills and act as a design variant as it is implied in Visser's work.

\section{Design One But in Different Forms}

The generic-design hypothesis by Goel and Pirolli (1992) formulates that "problem spaces exhibit major invariants across design problem-solving situations and major variants across design and nondesign problem-solving situations.
Zimrig and Craig (2001) also investigate domain independence of design. However, they suggest that widely accepted characteristics of design such as abductive reasoning, construction, ill-defined problem solving skills are not accurate enough to unite design across other fields of design or distinguish it from other types of problemsolving activities. So they investigate it through what they call mid-level processes named as mental simulation, decision-making, and analogical reasoning.

Visser (2009) confirms that there are both significant similarities between the design activities carried out in different situations and significant differences between design and other cognitive activities as stated in the generic design hypothesis. Then she takes on a slightly different approach and suggests that although design has specific characteristics that distinguish it from other cognitive activities, it also takes on different forms (2006) depending on the main dimensions of the design situation. Three dimensions that Visser supposes underlie differences between forms of design are design process, the designer and the artifact. Under each of these dimensions she proposes other variables and this study focuses on design tool as a design variant.

Tool

According to Michotte and Thines (1963-1991) action is regarded as the production of an event in which the actor participates. In a tool use event, the actor is producing an event, where the desired outcome in the beginning is the final state. In this event, the actor has the role of the "motor" object (van Leeuwen, et. al. 1994). Therefore, the tool user is involved not only as an observer but as a maker as well. In other words, the actor starts a dialogue with his tool. He feeds it with motor forces and perceives the results of the forces through the external representation constructed, and exerts a new set of forces if necessary.

An actor uses tools to make environmental resources serve its needs (van Leeuwen, et. al. 1994). However, the tool manifests the way in which the actor must tailor itself to environmental conditions (van Leeuwen, et. al. 1994) while the actor intends to move towards an end product thus; creates a tension between the goal of the actor, the means to achieve it and the end product. This is strongly the case in terms of design problems which are characterized as ill-defined problems, where neither the end goal nor the intermediate states are pre-defined. Both the definition of a design problem and the goal may be re-defined along the design process as the dialogue between the designer (actor) and his environmental resources including tools and the representation they have constructed proceeds.

Tool as a Variant in Design

Norman (1993b) states that tools, therefore represen- 
tation, and the human cognition co-evolve. (Norman, 1993b) Before postulating how this is possible in terms of design, we may look at it, at the scale of development of human cognition. According to this, Mervin Donald postulates four evolutionary stages in the development of human cognition: episodic memory, mimesis, mythic, external representation. The last evolutionary stage in the human cognition, the external representation, is defined by Donald as follows:

"The final stage is that of the modern human. Today our abilities to mime, use language, and reason are expanded through the power of writing, external representations, and tools. In other words, in today's world, we have taken evolution into our own hands, providing external devices- what I have called "cognitive artifacts"- to expand our abilities beyond that which our biological heritage alone makes possible. The future of human evolution is through technology." (Norman, 1993b)

Kirsh presents an affirmative view to that of Norman's. Kirsh states that, materiality plays a role in cognition by explicitly involving visual and motor cortex and when a structure is viewable and drawable, its properties prime a constellation of associations. This is apparent whenever a tool is in hand. Rulers prime measuring actions and thoughts; protractors encourage thought of angles and degrees. (Kirsh, 2010) Kirsh explains why most young people can no longer do much arithmetic in their heads through expanded use of calculator. Tools reshape the cost structure of task performance. (Kirsh, 2010) Tools are created to reduce the cost in terms of cognitive load that one needs in order to complete current tasks, or make it possible to achieve what is otherwise not possible.

Design tools also have the same impact during design process. They not only alter forms of representation but also the way architects think and approach the whole process. Thus, they are viewed as a design variant in this study. The following section attempts to make a record of this change through the marking the types of external representations in time and what they represent in terms of architectural stance.

\section{The Study: Communicating Design}

Architectural representation acts as tools of communication of those ideas generated during design through a visual form. In order to represent a design idea, scale models, sketches, renderings, perspective drawings and photographs are used most frequently. (Kalay, 2004) When communicating a design idea, representation types that explain the project best are preferred. The intent is to convince the audience that the design solution is a good solution to the design problem in hand. To achieve this, the graphics have to speak for the project. The main de- sign idea should be able to reveal itself through the way it is represented. Sole image of the proposal is not always enough. The reviewer needs additional graphic representations that reveal intangible information about the design to fully comprehend it. Architects produce plans, sections, elevations, scale model, diagrams, flow charts, exploded axons to make the project as explicit as possible. (Orbey \& Gürel, 2013) The difference between these representation types is defined as either yielding the "receiver to be an active participant in the communication process, or pass the idea directly to the receiver". (Kalay, 2004)

As printing technology evolved and digital design tools became ubiquitous, they made indispensible impact on graphic representation of a design which we have previously related to reflection of design stance of the architect. In 1970's, a project was represented solely with its technical drawings such as plans, sections and elevations. However, due to technological restrictions of the time, they were far from being explanatory and acted more as shop drawings or technical reports. These drawings are referred to as "static" by Kalay (2004). The drawings were made by hand and there was no way of altering them so that reviewers other than the client and the contractor could not be involved in the process. These representation norms have also been necessary as they are today. Today, these technical drawings are enhanced with sketches, perspectives and other graphical materials. Therefore, we should review the gradual change of graphic representation norms and attitudes. The hypothesis is that, graphic representations of an architectural design have become more analytical and revealing in terms of how the building will behave once it starts functioning as well as the process leading to the particular solution as digital representation tools became more available in time..

In order to support this argument, a collection of examples relevant to a 40 years span of timeline is utilized and has made this tool dependent shift in graphic representation in architectural design comprehensive. A paradigm shift from sketches to orthogonal drafted representations of design proposals was expected to evolve into photorealistic renders, exploded axons and more descriptive diagrams regarding performative analysis, function and expected behavior of the building and algorithms.

In this study, architectural graphic representation is taken as a reflection of architectural design stand. Results regarding the design approach adopted are driven through analyzing its graphic representation. According to this, Yapı Magazine was retrieved from 1973 to 2015 to investigate the change in architectural graphic representation.

\section{Method}

This study attempts to demonstrate a relation between the shift in graphic representation and design stand of ar- 
chitects in respect to architectural press, Yapı Magazine. Yapı, the oldest established magazine still in press today in Turkey, is taken as a tool in order to investigate the chronological period between 1973, the year Yapı had first been published, and 2015 to understand how digital tools have affected architectural representation and the way it is passed on to the audience. Yapı Magazine, as a tool to navigate through time and variety of projects, has provided data for claimed mutual evolution between digital design tools and architectural design approach that is read off architectural graphic representation. Three issues in each year were examined. These issues are January, May and September - so that the publishing is followed with 4 months interval for the last 42 years.

The retrieval process consists of three phases: extraction of types of graphic representation; quantification of these types and evaluation of the data.

The data collected in the first phase has been grouped into categories as follows: plans, section, elevations, partial details, 3D renders, 3D digital perspectives - wireframe and axonometric views, sketches, hand drawn perspectives, diagrams, physical model photographs and photographs.

In the second phase, these graphics were quantified to see how intensely they are utilized. In addition, 3D digital perspectives - wireframe and axonometric views as also referred to as other 3D digital products, and diagrams were assessed in terms of for what purposes they were used so that they may be related to possible tool developments.

And in the third phase, an assessment of the nature of representation belonging to one category during the span of 39 years were compared qualitatively to investigate how that certain types of representation have evolved in time.

\section{Results}

Yapı Magazine was retrieved between 1973 and 2015. Relevant issues in 1973, 1977 to 1982, 1984 and 1986 to1987 were either could not be found or has been observed not to contain any design projects. It is almost with 1990 that design projects are published with consistency and it is after 2001 that the magazine publishes multiple design projects in each issue. According to this, a total of 199 design projects were recorded in terms of which representation types they have used.

The first phase of the study shows that plan, section, elevation, detail (construction drawings) 3D renders, 3D digital wire-frame/perspective/axonometric views, sketches, hand drawn perspectives, diagrams and physical model photographs (explanatory drawings) and photographs are used collectively with varying amounts in time.

In the second phase, as already expected, the results show that plans, sections and elevations as conventional architectural representation types are used the most. It

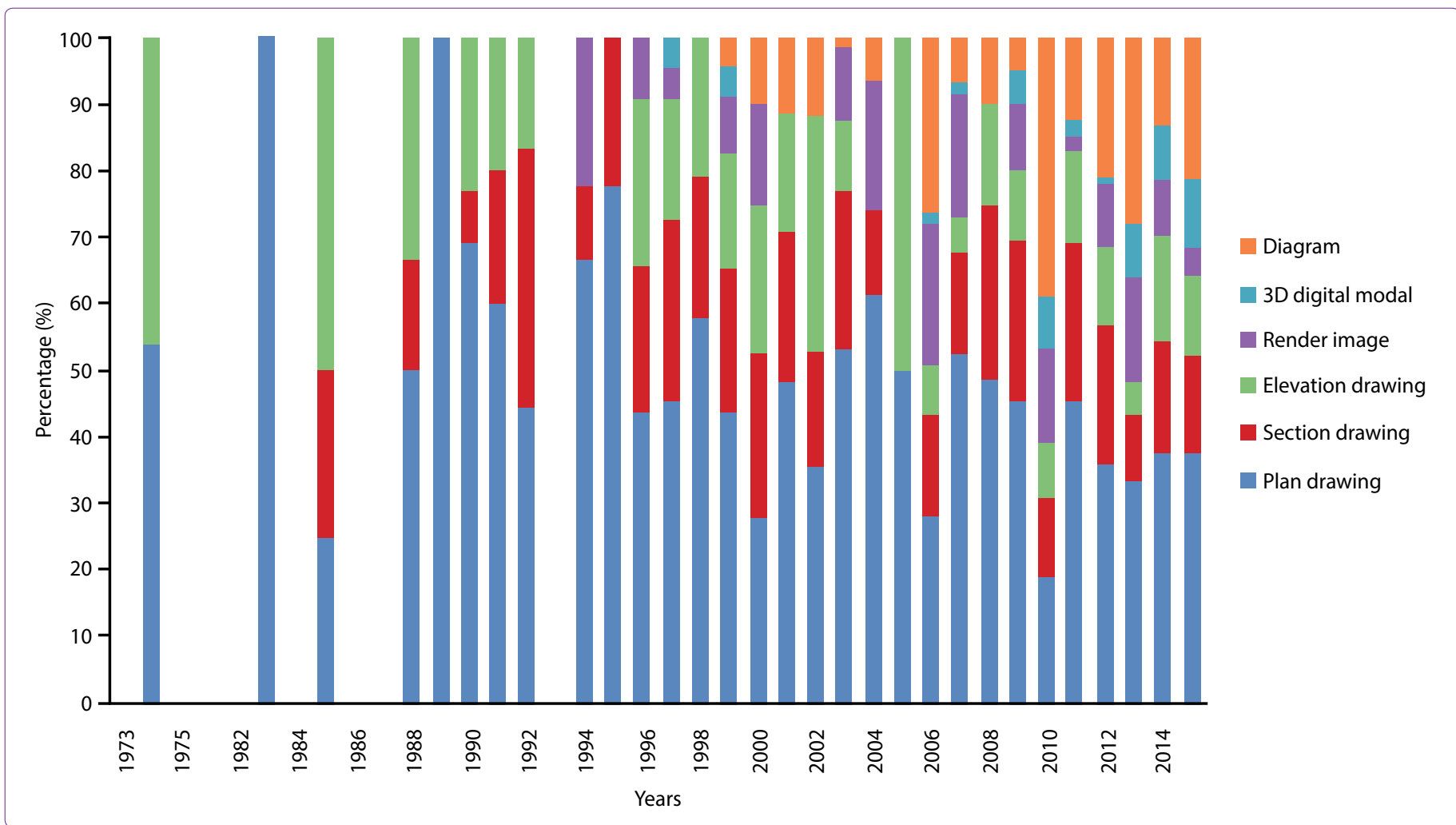

Figure 1. Distribution of representation types among years. 
should be noted that actual photographs of the buildings are the most frequently used representation type. However, this was omitted in the results so that the evaluations can be made within those types of representation that are involved during the design process. Beginning with 1994, $3 \mathrm{D}$ renders as well as diagrams and other $3 \mathrm{D}$ digital products start to enhance architectural representation medium. In the table below, a bar is dedicated for each year. Each graphic representation type is assigned a color and bars are segmented according to their percentage of use. The increase in the variety of colors between 1973 and 2012 represents the variation in representation medium used in presenting architectural design projects (Figure 1).

The graph above is divided into two (Figure 2 and Figure 3) to demonstrate consistency in presenting architectural work through conventional forms in one hand and the emergence of new types of representation on the other.

As it may be read on the figure below, first 3D render has been encountered in 1994, first 3D digital product consisting of wireframe, perspective or axonometric views with no intention regarding photo-realistic images in 1997 and first diagram is encountered in 1999. It may also be observed that use of diagrams is usually aligned with use of 3D digital products and 3D renders are always the most preferred type of representation among these three (Figure 3).

The third phase of this study was an evaluation of qualitative features of the architectural representations recorded. In the last years digital technology has influenced architectural representation and transmission of design ideas with new methods and tools. With new possibilities of expression in architecture, transmission of ideas has differentiated from traditional architectural representations.

In this direction, the presence of multi-disciplinary ap-

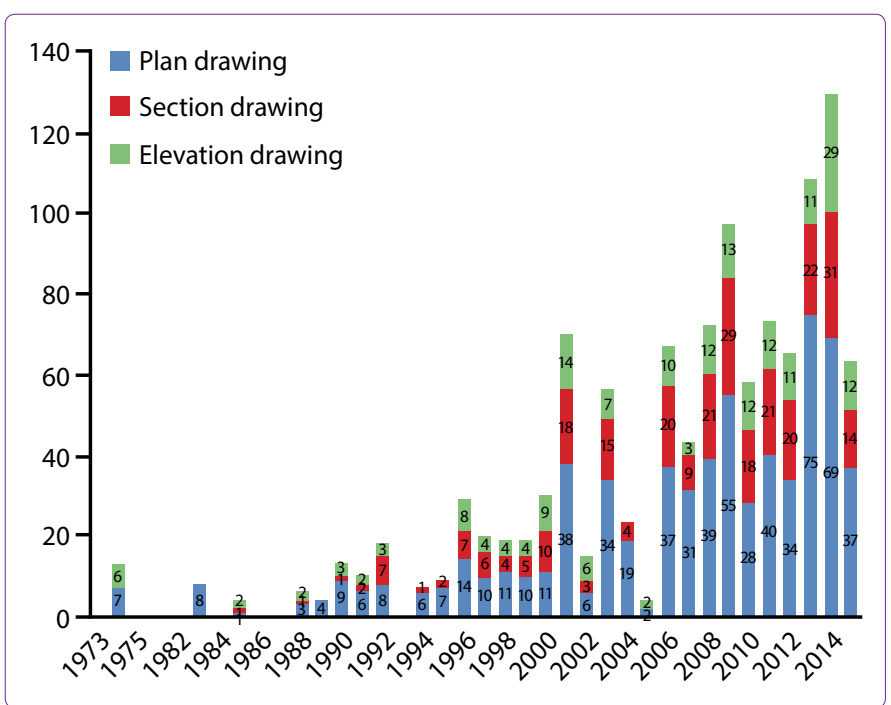

Figure 2. Plan-section and elevation drawings. proach such as graphic techniques based on diagrams and schematic drawing, the use of abstract representations, simpler and cartoonish drawings, the presence of simple mathematical expressions can be found in architecture milieu. Previously, architectural representation was a language that can be understood only by architects, planners and related disciplines but now it is transformed into a language that can be understood by everyone. Even cpnventional representations such as plan, section and elevation have transformed into a simpler and schematic form with reduced level of detail and high level of abstraction.

As Kalay (2004) mentioned, main mechanism that transforms an idea into a communicable message is abstraction. Abstraction extracts and filters the meaning of the message, focusing attention on its important characteristics. Higher degree of abstraction makes communication more efficient and it helps to focus the receiver on the parts of the message that the architect considers most important. According to the results of the third phase, simple graphical expressions, schematic drawings and diagrams become new strategies in order to communicate design ideas to others.

\section{Evaluation of Results}

Use of digital graphic software in design starting in early 1990s have yielded production of 3D products and diagrams -several years after the first 3D product has been notedeach conveying a certain type of message and in a certainly different way compared to that of present in 1970s. The following sections will discuss how this is related to design nature representing a change in architectural stance that takes the architect as an orchestra conductor or the "master builder" instead, assigns him an intellectual role.

\section{What Diagrams Tell}

Diagrams provide a descriptive medium of communica-

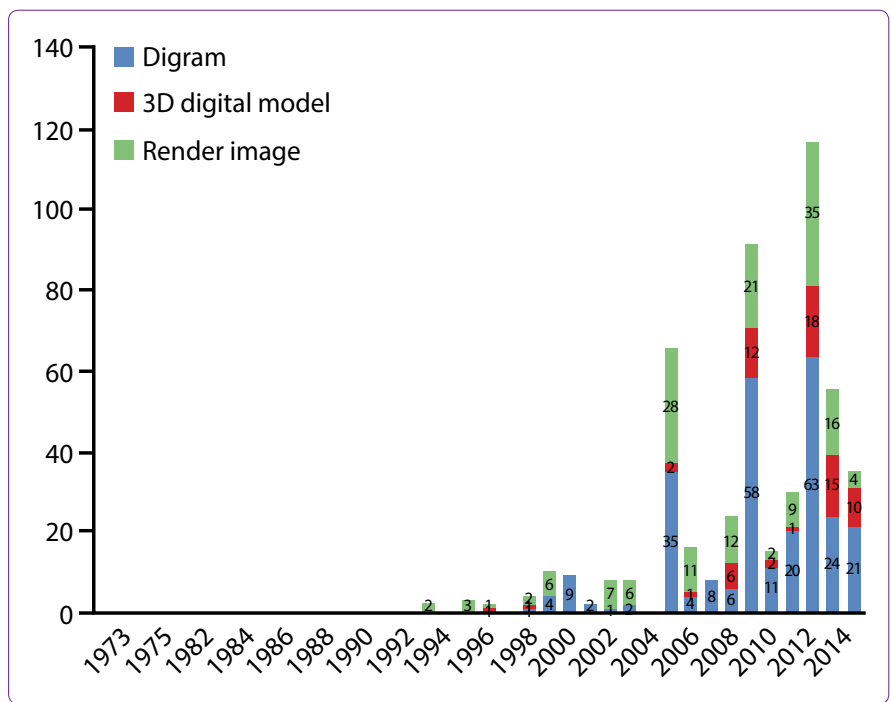

Figure 3. Beginnings of representing with 3D digital media and diagrams. 
tion for the sake of architectural representation. The most important feature of a diagram is it works across linguistic and cultural boundaries. (Kalay, 2004) Another important feature of diagrams is that they tell stories regarding the evolution of an architectural idea. They may be referred to as inclusive and dynamic. They allow any viewer into the process of form in formation. Contrary to conventional ways of architectural representation, they do not act as final reports of a process but describe the process itself. They "explore, explain, demonstrate or clarify relationships among parts of a whole". (Kalay, 2004) Similarly, according to Rowe (1987) diagrams are used to explore, analyze and synthesize ideas. Diagrams may be utilized to establish design principles that help the designer reflect on and prepare for following explorations. (Rowe 1987)

Architectural diagrams do not only represent physical elements, but also forces and flows. In the early phases of designing, architects draw diagrams and sketches to develop, explore, and communicate ideas and solutions. Design drawing is an iterative process. It involves externalizing ideas to store them and recognizing functions as well as finding new forms and integrating them into the proposal. Thus drawing is not only a vehicle for communication with others. It also helps designers understand the forms they work with. (Edwards 1979; Do and Gross, 2001)

We should note that this had not been the case prior to appearance of 3D models. 3D modeling software has made production of a simplified version of the building mass possible. The graphic software has made it possible to put additional information that represents decision process, acts and flows evaluated in the design process.

\section{What 3D Products Tell}

According to Lopes (1996) due to techno cultural changes, pictures are re-emerging. They now play a role in terms of storage, manipulation and communication of information.

Beginning with 1994, 3D render images have evolved into photo-realistic images where the design idea is presented as a finished product. This representation type is specifically chosen for marketing purposes rather than aiding design development phase. These images are used to aid those who are not architects or professionals in familiar fields but individuals who cannot understand construction documents.

Although this representation medium needs to be evaluated separately from diagrams and other 3D digital products, it also serves for the same purposes: inclusion and exposition. Similar to diagrams, 3D render images also tell stories. They are used to reveal how the space designed acts during different times of the day or different days of the year. Through the photo-montages made, they give clues regarding how the spaces may be used and what kind of atmosphere will take place once it's inhabited.
These images are used for expressing a certain experience provisioned for designed space.

According to Bares-Brkljac (2009), these images inherit accuracy, realism and abstraction. It is through these features that non-professionals believe in what they see. According to this, accuracy aids non-professionals to be acquaintance with the space. The relation that the nonprofessionals establish with the space is related to scale, distances and relations of volumes and spaces as well as to chosen vantage points. Human eye angles are preferred on purpose so that the viewer can imagine himself in the setting. Realism is one of the features that helps the viewers understand and evaluate the proposal the same way they perceive the environment.

\section{On Abstraction}

Abstraction is another key feature that contributes to understanding of the non-professional by referring to reduced information about design at a certain level. A high level of abstraction may not sufficiently present the proposal and a low level of abstraction may overwhelm the viewer with the information he does not need and understand. According to Bares-Brkljac (2009), the collective effect of accuracy, realism and abstraction in relevance to the form, influence observer's perceptual responses. And now the architect is in charge of defining the level of abstraction necessary to communicate the design idea as part of his intellectual new role in the profession.

\section{Conclusion}

Evolution of technology has altered the way architects practice. Emergence of new digital tools and new representation types in the architectural design process has enriched the way architects communicate their work. And how they represent their work is here associated with their stand through what these new representation types offer. According to this and through the data retrieved from Yapı Magazine with regard to the use of representation types, this study may conclude that architects have become more process oriented, expository, transparent in terms of reflecting the design process, inclusive rather than exclusive or isolating, abstract as well as more precise in revealing experience where on the contrary it had been all about communicating the information to the contractor to build the project. (Orbey \& Gürel, 2013) In other words, it has altered the relationship is defined between the architect and his audience.

\section{Discussion}

Tools dictate methods that affect architects' understanding and practice. This has been demonstrated in the study by showing how tools of design have yielded new ways to communicate and has re-defined architect's relation with his audience. 
It should make us wonder what else it changes. We have seen a shift from "the master builder" to an intellectual role of solely designing in terms of the role an architect plays in the profession.

In addition to how an architect practices or how he communicates his design, how he starts to think should also be asked. Like a teenage doing much of his calculations with a calculator, which cognitive abilities does he loose? Or like another one doing a lot of hyper-reading that help him increase chances to survive in an information rich environment, which cognitive abilities does he gain that help him to survive as a benefit of new tools he adopts. This leads us to the significance of an investigation that needs to be conducted in the field of cognition with regard to how tools affect the way a designer thinks.

\section{References}

Bares-Brkljac, N. (2009) "Assessing perceived credibility of traditional and computer generated architectural representations", Design Studies, 30, 415-437.

Coleman, R. (1988) The art of work: an apitaph to skill, London: Pluto Press.

Do, E. and Gross M. (2001) "Thinking with diagrams in architectural design", Artificial Intelligence Review, Kluwer Academic Publishers, Netherlands, 135-149.

Edwards, B. (1979) Drawing on the Right Side of the Brain: a course in enhancing creativity and artistic confidence, Los Angles, J. P. Tarcher.

Giedion, S. (1969) Mechanization Takes Command, Oxford University Press.

Gregotti, V. (2010) Architecture, Means and Ends, Chicago, USA: University of Chicago Press.

Ingold, T. (2000) Perception of the environment: Essays on livelihood, dwelling and skill, New York, NY, USA: Taylor and Francis Group.

Kalay, Y., (2004) Architeture's New Media, MIT Press.

Koutamanis, A. (2000) "Digital architectural visualization", Automation in Construction, 9, 347-360.

Lawson, B. (1980) "How Designers Think", The Architectural Press, London.
Lopes, D.(1996) Understanding Pictures, Clarendon, Oxford.

Menges, A. (2010) "Instrumental Geometry", in Corser, R. (eds), Fabricating Architecture, Princeton Architectural Press, New York, pp. 22-41.

Oxman, R. (2000) "Design media for the cognitive designer", Automation in Construction 9, 337-346.

Orbey, Betül \& Gürel, Nihan. (2013), Digital Design Tools vs. Architectural Representation: A Reading off Architectural Press, Stouffs, R. and Sariyildiz, S. (eds.), Computation and Performance Proceedings of the 31st eCAADe Conference Volume 2, Faculty of Architecture, Delft University of Technology, Delft, The Netherlands, 18-20 September 2013, s. 415-423, ISBN 978-94-91207-05-1.

Piedmont-Palladino, S. (2007) Tools of Imagination, New York: Princeton Architectural Press.

Pittman, John. (2003) "Building Information Modeling: Current Challenges and Future Directions", Ed.: Branko Kolarevic Architecture in the Digital Age: Design and Manufacturing, New York: Taylor and Francis, pp.254-8.

Purcell, A.T. and Gero, J.S. (1998) "Drawings and the design process", Design Studies, 19, 389-430.

Rowe, P. (1987) Design Thinking, Cambridge: MIT Press.

Schon, D.A.,Wiggins, G.(1992) "Kinds of seeing and their function in designing", Design Studies 13 Ž1992. Pp.135-156.

Sert, G. B. (2006) “A Survey On Photographic Representation In Architectural Magazine Covers: Covers Of Arredamento Mimarlik", Unpublished Master Thesis, METU, Ankara.

Visser, W. (2006) "Both generic design and different forms of designing", Wonderground, the 2006 DRS (Design research society) International Conference, Lisbon, Portugual, Novemver 1-4. http://hal.inria.fr/inria-00118256/en

Volti, R. (1992) Society \& Technological Change, New York: St. Martin's Press, Inc.

Willis, D. and Woodward, T. (2010) "Diminishing Difficulty: Mass Customization and the Digital Production of Architecture", Ed.: Corser, R., Fabricating Architecture, Princeton Architectural Press, New York, pp. 178-213.

Zimrig, C.M., Craig, D.L. (1994) “Defining design between domains:an argument for design research a la carte" Ed.: C Eastman, M McCracken and Wnewstetter Design Knowing and Learning: cognition in design education, Elsevier Science, Amsterdam pp 125-146. 